\title{
Abordagens ecossistêmica e comunicativa na implantação de Agendas territorializadas de desenvolvimento sustentável e promoção da saúde
}

\author{
Ecosystemic and communicative approaches \\ in the implementation of territorial agendas \\ for sustainable development and health promotion
}

Edmundo Gallo ${ }^{1}$

Andréia Faraoni Freitas Setti ${ }^{2}$

${ }^{1}$ Escola Nacional de Saúde Pública Sérgio Arouca,

Fiocruz. Av. Brasil 4.365,

Manguinhos. 21040-360

Rio de Janeiro RJ.

gallo@fiocruz.br

${ }^{2}$ Centro de Relações

Internacionais em Saúde,

Fiocruz

\begin{abstract}
This paper analyzes the sustainability of ecosystemic and communicative approaches in terms of strategic planning for the implementation of territorial agendas that seek to integrate the principles of Sustainable Development and Health Promotion. It takes the Sustainable Development and Health Promotion project: Implementation of the Healthy Cities Agenda integrated with Agenda 21 in Traditional Communities of Protected Areas of the Bocaina Region" as a point of reference. It involves action-research that strives to contribute to the promotion of quality of life by means of the implementation of a participative strategic agenda and the promotion of mutual economic sustainability. The work seeks to build theoretical/practical bridges between the approaches and the methodologies and technologies used, assessing their consistency and effectiveness in relation to the principles of sustainable development and health promotion, especially in the empowerment of the local population and the broadening of the autonomy of the community.
\end{abstract}

Key words Territorial agendas, Sustainable development, Health promotion, Healthy cities, Agenda 21, Autonomy
Resumo O trabalho analisa a adequação das abordagens ecossistêmica e comunicativa do planejamento estratégico para a implantação de agendas territorializadas integradoras dos princípios do Desenvolvimento Sustentável e da Promoção da Saúde. Utilizando como referencia o projeto Desenvolvimento Sustentável e Promoção da Saúde: Implantação da Agenda Cidades Saudáveis integrada à Agenda 21 nas Comunidades Tradicionais de Áreas Protegidas do Mosaico da Bocaina, uma pesquisa-ação que objetiva contribuir para a promoção da qualidade de vida por meio da implantação coletiva de agenda estratégica local e promoção da sustentabilidade econômica solidária. $O$ trabalho busca construir pontes teórico-práticas entre as abordagens e a metodologia e tecnologias utilizadas, avaliando sua coerência e efetividade em relação aos princípios do desenvolvimento sustentável e da promoção da saúde especialmente no empoderamento da população local e na ampliação de autonomia da comunidade.

Palavras-chave Agendas territorializadas, Desenvolvimento sustentável, Promoção da saúde, Cidades saudáveis, Agenda 21, Autonomia 
Desenvolvimento, Meio Ambiente e Saúde: a Agenda Contemporânea

A relação entre meio ambiente e desenvolvimento está no centro da Agenda global contemporânea, expressando tensionamentos profundos entre visões-de-mundo com maior ou menor grau de antagonismo. Nos polos encontram-se aqueles que defendem a continuidade do modelo atualmente hegemônico e os que advogam a conservação radical. Entre estes há um espectro de posições que buscam o equilíbrio entre desenvolvimento e preservação, em uma perspectiva de promoção da equidade e da sustentabilidade socioambiental ${ }^{1-8}$.

Este debate se desenvolveu especialmente nos últimos vinte e cinco anos, saindo dos círculos mais restritos da academia e dos ambientalistas para ganhar o espaço da formulação e indução de políticas públicas e privadas, notadamente a partir de organismos internacionais multilaterais, culminando na adoção de um conceito de desenvolvimento sustentável que [...] consolida uma visão crítica do modelo de desenvolvimento adotado pelos países industrializados, reproduzido pelas nações em desenvolvimento, que ressalta a incompatibilidade entre os padrões de produção e consumo vigentes, o uso racional dos recursos naturais e a capacidade de suporte dos ecossistemas ${ }^{9}$.

O marco inicial é a aprovação pela Assembléia Geral da ONU do relatório Our Common Future (Nosso Futuro Comum), mais conhecido como Relatório Brundtland, publicado em 1987 pela Comissão Mundial para o Meio Ambiente e Desenvolvimento. Nele é formulado o conceito "clássico" de desenvolvimento sustentável: "development which meets the needs of the present without compromising the ability of future generations to meet their own needs", concebido como processo de transformação no qual a exploração dos recursos, a direção dos investimentos, a orientação do desenvolvimento tecnológico e a mudança institucional se harmonizam e reforçam o potencial presente e futuro, a fim de atender às necessidades e aspirações humanas ${ }^{10,11}$.

A adoção pela ONU deu peso político ao conceito, que teve seus princípios pactuados pelos países em 1992, no Rio de Janeiro, na Conferência das Nações Unidas para o Meio Ambiente e Desenvolvimento (ECO 92), materializados em cinco documentos: Declaração do Rio de Janeiro sobre o Meio Ambiente e o Desenvolvimento; Convenção sobre Mudanças Climáticas; Declaração de Princípios sobre Florestas; Convenção sobre a Biodiversidade e Agenda 21 Global $^{12}$.
O relatório Brundtland também explicita a natureza e a escala dos problemas ambientais, sociais e econômicos a serem enfrentados e propõe o desenvolvimento sustentável como estratégia para reverter o quadro mundial de pobre$\mathrm{za}$, desmatamento e desigualdade social.

Com efeito, $[. .$.$] a lógica predominante de$ utilização do meio ambiente ainda se guia pela busca de lucros e acúmulo de capital, e não em nome das necessidades sociais, o que agrava e acelera o desequilíbrio ecológico, contribuindo para a ampliação das desigualdades sociais" ${ }^{\prime 13}$. Neste sentido, o grau de inserção ou de exclusão social pode ser entendido tanto como determinante da sustentabilidade ambiental quanto do processo saúde-doença ${ }^{14,9}$.

Em todo o mundo, a pobreza e as condições de vida insatisfatórias permanecem sendo um dos principais determinantes do adoecimento. Dados contidos no "Relatório de Desenvolvimento Humano 2007/2008: Combater as alterações climáticas - solidariedade humana num mundo dividido", publicado pelo Programa das Nações Unidas para o Desenvolvimento (PNUD), revelam a vulnerabilidade da população mais pobre: a grande maioria das 10 milhões de crianças que morrem anualmente antes de atingirem os cinco anos de idade tem como determinantes a pobreza e a subnutrição ${ }^{15}$.

Este quadro levou a ONU a adotar na Declaração do Milênio oito objetivos a serem atingidos até 2015: Erradicar a pobreza extrema e a fome; Atingir o ensino básico universal; Promover a igualdade entre os sexos e a autonomia das mulheres; Reduzir a mortalidade na infância; Melhorar a saúde materna; Combater o HIV/ AIDS, a malária e outras doenças; Garantir a sustentabilidade ambiental; e, Estabelecer uma parceria mundial para o desenvolvimento ${ }^{16}$.

A Cúpula Mundial para o Desenvolvimento Sustentável, em Johannesburgo, 2002, influenciada pelos Objetivos de Desenvolvimento do Milênio (ODM) e pelas necessidades dos países em desenvolvimento, reforçou a tendência de vincular cada vez mais o desenvolvimento sustentável, para além das questões ambientais, ao desenvolvimento social e econômico ${ }^{11,17}$.

Tendo como base a determinação social da saúde, três áreas em especial passaram a desenvolver teórico-praticamente a relação entre meio ambiente, desenvolvimento sustentável e saúde: promoção da saúde, saúde ambiental e complexo produtivo da saúde.

A promoção da saúde é definida como o processo que possibilita às pessoas aumentar seu 
controle sobre os determinantes sociais da saúde e através disto melhorá-la. Portanto, a promoção da saúde representa um processo social e político, não somente incluindo ações direcionadas ao fortalecimento das capacidades e habilidades dos indivíduos, mas também ações direcionadas às mudanças das condições sociais, ambientais e econômicas para minimizar seu impacto na saúde individual e pública ${ }^{18}$.

A saúde ambiental busca olhar [...] o papel do 'ingrediente' chamado ambiente sobre a saúde, não de forma isolada ou linear, mas contextualizado e inserido na complexa trama da determinação da saúde das populações ${ }^{14}$.

O desenvolvimento do potencial econômico e de inovação do Complexo Produtivo da Saúde, e a geração de consumo, emprego, lucro e distribuição de renda dele advindas, [...] deve considerar a garantia das necessidades sociais básicas, mais vinculadas à garantia do bem-estar social, articulado ao crescimento econômico sustentável com equidade e justiça social ${ }^{19}$.

Essas abordagens reforçam a assertiva de que o desenvolvimento sustentável [...] calls for a convergence between the three pillars of economic development, social equity, and environmental protection $^{11}$. Porém, ainda que haja consenso sobre esse novo paradigma, assim como um conjunto de estratégias em curso para promovê-lo, é consensual que os principais desafios relacionam-se à efetividade de políticas, pesquisas e a outras ações concretas ${ }^{20,21,09,14}$.

A realização da Rio+20, em 2011, chama ainda mais a atenção para estes desafios, já apontados em diversos momentos, como na Conferência Nacional de Saúde Ambiental, na Comissão de Determinantes Sociais da Saúde, na Política Nacional de Promoção da Saúde (PNPS), e nas ações e deliberações da ONU, indicando para estratégias teórico-práticas de construção de territórios sustentáveis e saudáveis por meio da implantação local de agendas sociais - Agenda 21 e Cidades Saudáveis ${ }^{15,22-25}$.

\section{Para uma abordagem integradora de Saúde, Meio Ambiente e Desenvolvimento}

Foi fundamental a institucionalização e o grau de consenso alcançado pelo desenvolvimento sustentável enquanto novo paradigma e princípio estruturante para o desenvolvimento, permitindo o avanço na criação de tecnologias, elaboração de indicadores e no envolvimento governamental, social e comunitário. Entretanto, ainda há dimensões conceituais a serem esclarecidas, e é gritante o gap entre os consensos institucionais e teóricos e sua aplicação prática, demandando parcerias globais e um conjunto de ações locais para que a sustentabilidade ambiental seja efetivamente incorporada às políticas, programas e projetos locais, promovendo a equidade e a justiça ambiental $9,11,14,16,26$.

Para responder a estes desafios, diversas abordagens teórico-metodologicas têm procurado construir instrumentos que permitam a produção de conhecimento e a ação sobre os objetos a elas relacionados partindo do consenso de que os principais desafios relacionam-se à efetividade de políticas, pesquisas e a outras ações concre$\operatorname{tas}^{9,14,20,21}$.

Com efeito, ainda que se concorde com a impossibilidade de manutenção do atual modelo hegemônico de produção, este ainda tem capacidade tecnopolítica de reproduzir seu modo de produção e as consequências do mesmo. Em contrapartida, ampliam-se experiências alternativas de organização econômica e social mais solidária e eficiente em relação aos indicadores macroeconômicos tradicionais ${ }^{11,14,24,25}$.

Em todas estas experiências, as abordagens destacam o território como categoria central. Toda investigação ou formulação parte de um território vivo, de uma territorialidade, entendida como o conjunto de valores e de práticas referidos a determinado espaço e em determinado tempo e que caracterizam a sua produção social, que se dá a partir e sobre uma realidade particular onde os vetores da racionalidade dominante entram em embate com a emergência de outras formas de vida, o que exige projetos e ações que sejam capazes de compreender e - consequentemente - de transformar as práticas sociais referidas a territórios, produzindo autonomia individual e coletiva ${ }^{7,27-29}$.

Este trabalho, usando uma experiência concreta como referência, apresenta os momentos metodológicos e discute a potência da abordagem ecossistêmica associada à abordagem comunicativa do planejamento estratégico-situacional, na implantação de uma agenda territorializada que buscou contribuir para dar materialidade à Agenda referida, apoiando a incorporação de territórios excluídos à cidadania, porém buscando evitar sua captura pela racionalidade dominante, estimulando a transformação do modelo de produção para uma economia e uma sociedade mais solidária e equânime.

Para tanto, adotou-se como pressupostos e resultados esperados: promover a equidade, a 
autonomia e a sustentabilidade por meio de estratégias que levem à justiça socioambiental, tendo como modo de gestão um processo de governança local. Para atender a essa perspectiva, utilizou-se um conjunto de categorias analíticas, capazes de direcionar a atuação sobre a interseção entre desenvolvimento, saúde e ambiente em um território concreto (Figura 1).

A territorialidade selecionada para referenciar os apontamentos metodológicos foi a primeira etapa do projeto Desenvolvimento Sustentável e Promoção da Saúde: Implantação da Agenda Cidades Saudáveis integrada à Agenda 21 nas Comunidades Tradicionais e Áreas Protegidas do Mosaico da Bocaina - Projeto Bocaina, uma pesquisaação que objetiva contribuir para a promoção da qualidade de vida, por meio da construção e implantação coletiva de agenda estratégica local (Comunidade Saudável); e para a promoção da sustentabilidade econômica solidária, incorporando-se às iniciativas em curso no Mosaico, voltadas para o turismo como arranjo produtivo preferencial.

\section{Abordagens Ecossistêmica e Comunicativa do Planejamento Estratégico-situacional: momentos metodológicos aplicados}

O primeiro momento metodológico é exatamente o da pactuação dos pressupostos, categorias e de seu significado, que constituem o Projeto de Governo enquanto valores e objetivos; e de seus meios e modo de gestão, que se volta para a ampliação da Capacidade de Governo.

Dentro desta perspectiva, o interesse pela $\mathrm{Ca}$ pacidade de Governo está mais focalizado no potencial de desenvolvimento das condições de possibilidade de atualização de um Projeto de emancipação através da inovação organizacional, embasada no estímulo ao desenvolvimento de sujeitos/ gestores autônomos e críticos. Projetos emancipatórios, inovação e autonomia são condicionados por pactos organizacionais produzidos por ações comunicativo-estratégicas ${ }^{26}$.

As abordagens ecossistêmica e comunicativa do planejamento estratégico-situacional voltado para o desenvolvimento sustentável atendem a essa perspectiva, pois pressupõem a participação social na gestão das políticas, particularmente da comunidade local, a partir da análise situaci-

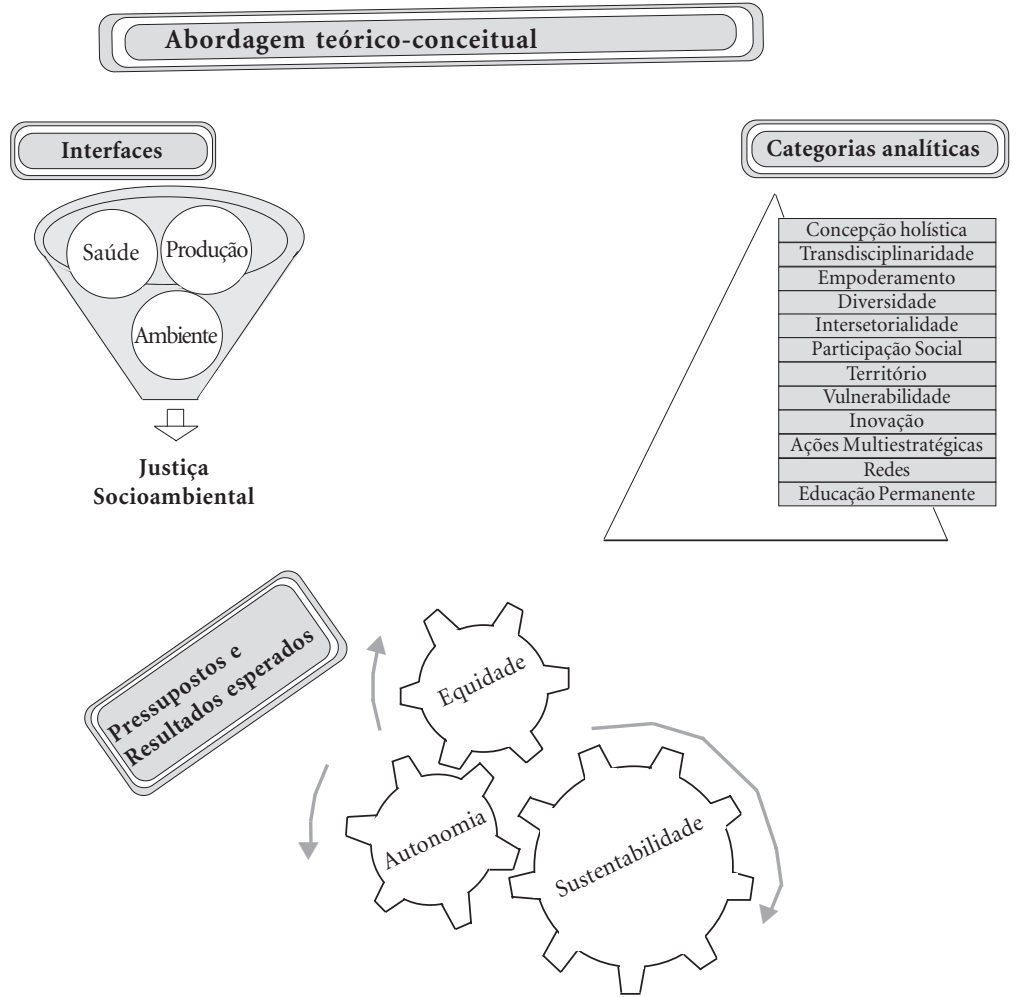

Figura 1. Abordagem teórico-conceitual 
onal e estratégica, produzindo e utilizando informações diversas que possibilitem demonstrar as interfaces entre bens e serviços dos vários ecossistemas. Também buscam estabelecer mecanismos de governança que abranjam as políticas ambientais, sociais e econômicas e que resultem em propostas de gestão integrada, a partir da formulação e efetividade de programas, políticas e projetos ${ }^{4,29-33}$.

Para estas abordagens, a promoção da Justiça Socioambiental está diretamente relacionada aos pressupostos da Equidade, da Autonomia e da Sustentabilidade, suportados pela Governança como modo de gestão. A seguir, explicitam-se estes pressupostos e modo de gestão tal como descritos na literatura e pactuados no âmbito do Projeto Bocaina.

\section{Justiça Socioambiental}

A Rede Brasileira de Justiça Ambiental adota este conceito como o [...] tratamento justo e (o) envolvimento pleno de todos os grupos sociais, in dependente de sua origem ou renda nas decisões sobre o acesso, a ocupação e o uso dos recursos naturais em seus territórios ${ }^{34}$. O conceito, portanto, mais que apontar para um resultado, refere-se ao processo de empoderamento e produção de autonomia, equidade e sustentabilidade, especialmente para as populações excluídas e/ou vulneráveis.

\section{Equidade}

Consiste em eliminar as diferenças desnecessárias, evitáveis e injustas que restringem as oportunidades para se atingir o direito de bem-estar alcançado por meio de políticas que viabilizem condições de vida favoráveis à saúde, priorizando grupos desprivilegiados e vulneráveis, buscando reverter às desigualdades sociais. A equidade está relacionada aos determinantes sociais. $\mathrm{Na}$ saúde, sua promoção implica em garantir o acesso envolvendo duas dimensões importantes: a equidade horizontal - tratamento igual aos indivíduos que se encontram em uma situação igual de saúde - e a equidade vertical - tratamento apropriadamente desigual aos indivíduos em situações distintas de saúde ${ }^{35}$.

\section{Autonomia (cognitivo-prática)}

Condição que se constrói na relação com o outro, na qual sujeitos individuais e/ou coletivos desenvolvem uma maior capacidade de compre- ender e agir criticamente, transformando a si mesmos e o seu contexto social em um sentido emancipatório, promovendo a capacidade do indivíduo de tomar decisões sobre a saúde, as relações sociais e sobre sua vida em três dimensões: Clínica, Sanitária e Ético-moral.

\section{Sustentabilidade}

Estilo de desenvolvimento com enfoque participativo de planejamento e gestão, norteado por um conjunto interdependente de postulados éticos: atendimento das necessidades humanas fundamentais, promoção da autoconfiança das populações envolvidas e cultivo da prudência ecológica ${ }^{36}$. As diretrizes para a sustentabilidade apontam tanto para uma racionalidade que garanta a solidariedade e a cooperação mundial, quanto para a continuidade do desenvolvimento e da própria vida para as gerações futuras.

Em relação à saúde, é preciso que haja uma reincorporação das questões do meio ambiente em suas políticas e práticas, bem como a integração dos objetivos da saúde ambiental numa ampla estratégia de desenvolvimento sustentável, em uma abordagem mais integrada e intersetorial ${ }^{35,37}$.

\section{Governança}

A categoria Governança pressupõe que sejam repensadas as relações entre Estado e Sociedade e Público e Privado a partir da perspectiva de uma gestão democrática. Tem a potência de estabelecer vínculos entre teoria e território pelo seu caráter operacional, instrumental-comunicativo $^{26,29}$. É descrita como:

[...] o sistema local de decisões fundadas em relações de parceria, acordo, negociação, cooperação entre os diversos sujeitos que compõem a cena política local, que permita a regulação coletiva dos interesses particulares. Dois são os princípios da Governança local:

- A identificação das forças sociais locais existentes na cidade e seus respectivos interesses;

- A construção de um pacto territorial em torno de três eixos: a inserção da economia local no novo modelo de desenvolvimento gerado pela reestruturação e globalização das economias regionais e nacionais; a garantia dos direitos urbanos que assegurem um padrão minimo de qualidade de vida, definido pelas condições habitacionais, urbanas e ambientais; e, a reforma da máquina administrativa local visando dotá-la das condições de eficiência e eficácia necessárias ao papel do poder público na 'governança' do município. 
A Agenda Comunidades Saudáveis:

Estratégia de Integração entre Saúde, Meio Ambiente e Desenvolvimento Sustentável

O segundo momento metodológico é o da seleção de uma Agenda territorializada que permita integrar as dimensões de saúde, desenvolvimento e ambiente. No Projeto Bocaina, foi a Agenda Comunidades Saudáveis que permitiu essa articulação. Para sua implantação foram definidos três eixos teórico-práticos: produção sustentável e saudável; políticas públicas de desenvolvimento e saúde; saneamento ecológico e habitação saudável, conforme Figura 2.

\section{Definição do território}

O terceiro momento é o da definição do território. Como apontado anteriormente, todo referencial precisa ser aplicado a uma situação concreta, a um território vivo e referido às territorialidades nele construídas, procurando compreender e interferir sobre as práticas que o reconstroem permanentemente. Para manter-se coerente com a abordagem, essa aproximação deve ter como base o interesse do gestor/pesqui- sador e da comunidade na promoção da justiça socioambiental, levando à seleção de territórios que demandem estratégias nesse sentido. Quando se fizer necessária uma definição mais focal, deve-se sempre fazê-la de forma participativa, utilizando a oportunidade como espaço de tematização da realidade local e de seus vínculos com outras escalas, promovendo a apreensão da abordagem, o conhecimento da situação e a geração de solidariedade entre os atores.

O Projeto tem por base o território do Mosaico Bocaina, que reúne unidades de conservação, de âmbitos federal, estadual e municipal e suas respectivas zonas de amortecimento, localizadas no Vale do Paraíba do Sul, litoral norte do Estado de São Paulo e litoral sul do Estado do Rio de Janeiro, abrangendo 09 municípios dos estados do Rio de Janeiro e de São Paulo, quinze Unidades de Conservação e suas zonas de amortecimento. A região integra o Corredor da Biodiversidade da Serra do Mar, um "hotspot", área prioritária para conservação, de alta biodiversidade e ameaçada no mais alto grau, contendo pelo menos 1.500 espécies endêmicas de plantas e que tenha perdido mais de $3 / 4$ de sua vegetação original, como é o caso da Mata Atlântica. O ter-

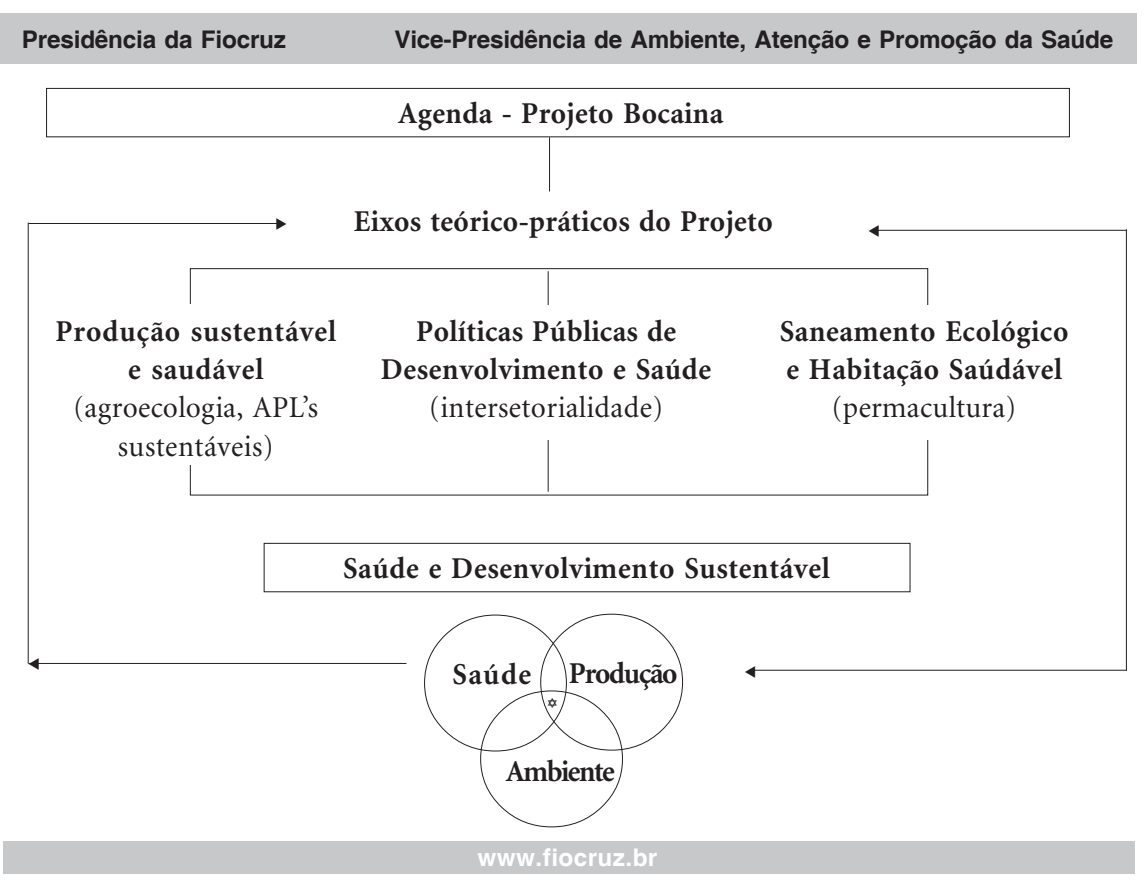

Figura 2. Agenda teórico-prática do Projeto Bocaina 
ritório do Mosaico abriga importantes maciços florestais totalizando cerca de 222 mil hectares, sob condições especiais de manejo e proteção legal. Abarca vinte e quatro comunidades tradicionais de três segmentos (doze caiçaras, sete indígenas e cinco quilombolas), estimando-se que o número de famílias seja de 120 Indígenas Guaranis, 280 Quilombolas e 240 Caiçaras. Inicalmente focaliza-se em duas comunidades caiçaras localizadas no município de Paraty, Estado do Rio de Janeiro.

A seleção preliminar do Mosaico respondeu à necessidade de apoiar a implantação local de uma agenda que trabalhasse as questões de saúde e ambiente articulada à agenda em curso, concentrada em questões de desenvolvimento sustentável, gestão e uso do território. Tal necessidade foi identificada pela análise de documentos e em reuniões com gestores locais e com o Fórum Regional de Comunidades Tradicionais do Sul Fluminense e Norte de São Paulo.

Portanto, o Projeto Bocaina integrou-se às iniciativas desenvolvidas a partir da mobilização das comunidades, que durante o I Encontro de Comunidades Tradicionais e Áreas Protegidas do Mosaico da Bocaina, promovido pelo Conselho Consultivo do Mosaico, havia definido dois eixos de ação: Gestão Participativa e Uso do Território e dos Recursos Naturais, tendo como desafios a sustentabilidade econômica solidária e a promoção da qualidade de vida ${ }^{38}$.

Em relação ao primeiro desafio, o turismo sustentável e de base comunitária havia sido selecionado como arranjo produtivo prioritário, e uma série de estratégias já haviam sido desencadeadas. Quanto ao segundo, apesar de aparecerem algumas ações de saneamento e educação, constatou-se que as mesmas eram insuficientes para se constituírem como agenda Comunidade Saudável, cuja implantação, integrada à Agenda em curso, surgiu, portanto, como demanda à Fiocruz.

Entretanto, ainda que o Projeto Bocaina pretendesse atingir o conjunto das comunidades do Mosaico, por limitações operacionais era necessário selecionar no máximo três, uma de cada segmento, trazendo para seus representantes a primeira decisão crítica: em uma situação de carência generalizada de bens e serviços e de segmentação das comunidades, que critérios adotar e que decisão tomar? O próximo momento descreve como isso se deu.

\section{Análise de Situação, Análise Estratégica e Definição de Estratégias}

A definição final das comunidades (terceiro momento) e a implantação da Agenda foram feitas por meio de Oficinas de Planejamento com representantes da comunidade e outros atores locais, em três etapas, que constituem o quarto momento metodológico: 1) Análise Situacional e Estratégica da Saúde local; 2) Integração da Agenda Comunidades Saudáveis à Agenda do Mosaico da Bocaina; e, 3) Definição de estratégias e ações para implementação da Agenda Comunidades Saudáveis.

As oficinas utilizaram ferramentas e abordagem comunicativo-estratégica voltada para a construção de pactos de reprodução e produção em espaços coletivos, adequada para a elaboração da agenda local ${ }^{28}$. A análise situacional foi complementada por análise bibliográfica e documental.

A dinâmica das oficinas foi concebida para atingir os objetivos propostos em uma perspectiva construtivista, estruturando o espaço de conversação por meio de método e instrumentos para facilitar a construção coletiva do projeto, privilegiando técnicas de registro e visualização coletivas e produção de consenso. Alguns procedimentos e instrumentos característicos do processo de planejamento estratégico foram utilizados para promover a apropriação do projeto, sua abordagem, principais conceitos e objetivos, bem como para a pactuação dos territórios, dos desafios e estratégias de ação. Foi utilizada a técnica de brainwriting moderado para seleção de problemas, definição do território e formulação e priorização de desafios, estratégias e ações.

Ao longo da discussão sobre o Projeto Bocaina, foram registrados em tarjetas os principais problemas identificados, constituindo um banco de problemas que caracterizavam a situação de saúde das comunidades. A partir deste banco e da definição preliminar, por parte do Fórum, de que a base territorial seria o município de Paraty, passou-se a discutir quais seriam as comunidades para a ação inicial do projeto.

A ideia inicial de contemplar uma comunidade de cada segmento (quilombola, indígena e caiçara) foi abandonada em função da compreensão, expressa pelos representantes quilombolas e indígenas, de que as comunidades mais carentes de serviços deveriam ser escolhidas, definindo-se como territórios iniciais de atuação do projeto duas comunidades caiçaras: Pouso da Cajaíba e Praia do Sono. 
Entretanto, considerando a importância de 1 - atender a demandas transversais que foram apresentadas (Abuso de álcool e outras drogas e educação sexual) relacionadas a todas as comunidades, 2- promover um processo de educação de caráter multiplicador e 3- qualificar as propostas de integração dos serviços de atenção das comunidades ao sistema de atenção de Paraty e região, a equipe do projeto propôs trabalhar com três desafios prioritários: o primeiro voltado para as duas comunidades, e o segundo e terceiro para o conjunto de comunidades. Estes desafios foram processados tecnopoliticamente para a sua qualificação e priorização e a seguir desenhadas as estratégias e ações necessárias para enfrentar cada desafio, o ponto focal ou pessoa referência e prazos para a execução do plano (Quadro 1).

\section{Avaliação de Coerência e Efetividade}

O quinto momento metodológico corresponde à avaliação de coerência e efetividade do projeto em relação aos pressupostos, categorias e resultados esperados em três dimensões: formulação, processo e resultado. A avaliação foi concebida como parte do processo de empoderamento comunitário e de desenvolvimento de competências individuais e coletivas, assim como de redirecionamento do projeto ${ }^{26,27,39,40}$.

Para realizar a análise de coerência da formulação do Projeto Bocaina, tomou-se como base a Matriz de Análise de Projetos Sociais sob enfoque do Desenvolvimento Sustentável e da Promoção da Saúde, que sistematiza a correlação entre estes enfoques ${ }^{9}$. Para aplicação dessa Matriz, a partir da categorização inicial, os documentos e as ações iniciais de implantação do Projeto tiveram seus conteúdos analisados e foram identificadas as ideias-chave relacionadas a cada grupo de categorias previamente integradas conceitualmente, como apresentada no Quadro 2.

Essa etapa da avaliação do Projeto comprovou que seus diversos componentes eram aderentes à abordagem adotada.

A segunda dimensão avaliativa, de processo, analisou a coerência e a efetividade do projeto em sua etapa de execução, a partir da observação participante, entrevistas e questionários. Foram utilizados: levantamento de opiniões; visitas de campo e observação direta; questionários pré-estruturados; e entrevistas com informantes-chave e roteiro previamente estruturado.

Os questionários e as entrevistas foram realizados ao final de cada uma das oficinas, para aferir a apreensão do projeto e dos conceitos de
Desenvolvimento Sustentável e Promoção da Saúde, bem como a percepção sobre a participação e a adequação da dinâmica das oficinas. A aplicação do questionário procurou avaliar se as oficinas atingiram seus objetivos: 1) ampliar o conhecimento sobre o Projeto e seus conceitos e 2) promover a participação efetiva dos representantes e avaliar a sua dinâmica. As entrevistas procuraram avaliar a correlação com os achados dos questionários e o grau de alcance dos objetivos da oficina, conforme Gráficos 1 a 4 .

A análise dos dados obtidos nos questionários e entrevistas permitiu constatar um alto grau de conhecimento sobre o significado e objetivos do projeto (Gráfico 1), de informação sobre os conceitos Desenvolvimento Sustentável e Promoção da Saúde (Gráficos 2 e 3) e de participação no Projeto Bocaina (Gráfico 4).

A terceira dimensão avaliativa, de resultado, analisou a efetividade do Projeto Bocaina em relação ao seu objetivo geral - Implantar a Agenda Cidades Saudáveis integrada à Agenda 21 nas Comunidades Tradicionais e Áreas Protegidas do Mosaico da Bocaina e sua coerência com a abordagem proposta.

O conteúdo dos desafios assumidos permite afirmar que houve a implantação da Agenda Comunidades Saudáveis e sua integração à Agenda do Mosaico da Bocaina no contexto da Agenda 21 local: 1) Ação Territorial Focal - organizar o sistema de coleta, tratamento e destino de resíduos domiciliares nas comunidades do Pouso da Cajaíba e Praia do Sono; 2) Ação Multiplicadora Transversal - desenvolver processo de educação em saúde com representantes das comunidades, priorizando os temas uso abusivo de álcool e outras drogas e educação sexual; e 3 ) Ação Territorial Transversal - realizar análise da situação de saúde e desenvolvimento sustentável nas comunidades do Mosaico e desenho de um modo de atenção integrada naquelas pertencentes ao município de Paraty.

Estes desafios têm potencial de problematizar e intervir sobre distintas dimensões da determinação social da saúde, articulando diferentes escalas e permitindo a integração à agenda voltada para a economia solidária, portanto potencialmente promotora de equidade e sustentabilidade. São, portanto, coerentes com os valores e pressupostos do Projeto de Governo.

Por outro lado, demandam e permitem a ação intersetorial e do conjunto de atores locais, permitindo o estabelecimento de mecanismos de governança que ampliem sua Capacidade de Governo. Isso se refletiu no estabelecimento de 
Quadro 1. Matriz de Desafios, Estratégias e Ações

\begin{tabular}{|c|c|c|}
\hline Desafios & Estratégias & Ações \\
\hline \multirow{5}{*}{$\begin{array}{l}\text { Organização da } \\
\text { coleta, tratamento e } \\
\text { destino de resíduos } \\
\text { domiciliares } \\
\text { (Saneamento básico / } \\
\text { construção de } \\
\text { módulos sanitários / } \\
\text { destinação de } \\
\text { resíduos domésticos / } \\
\text { contaminação de } \\
\text { mananciais / } \\
\text { Educação em saúde - } \\
\text { verminose) }\end{array}$} & $\begin{array}{l}\text { Elaborar diagnóstico da situação de } \\
\text { destinação dos resíduos domiciliares }\end{array}$ & $\begin{array}{l}\text { Mapear o caminho das águas; } \\
\text { Identificar os nós críticos de contaminação } \\
\text { da água }\end{array}$ \\
\hline & $\begin{array}{l}\text { Avaliar a qualidade da água } \\
\text { (consumo/uso) }\end{array}$ & $\begin{array}{l}\text { Realizar reunião da coordenação local do } \\
\text { projeto para planejamento da ação local; } \\
\text { Coletar e analisar a qualidade da água }\end{array}$ \\
\hline & $\begin{array}{l}\text { Desenvolver ações de educação e } \\
\text { saúde relacionadas }\end{array}$ & $\begin{array}{l}\text { Realizar reuniões nas duas comunidades } \\
\text { para apresentação do projeto }\end{array}$ \\
\hline & $\begin{array}{l}\text { Identificar possíveis alternativas } \\
\text { para destino adequado dos resíduos } \\
\text { domiciliares }\end{array}$ & Realizar Oficina de Ecossaneamento \\
\hline & $\begin{array}{l}\text { Buscar parcerias para implementar } \\
\text { o plano de coleta, tratamento e } \\
\text { destino dos resíduos domiciliares }\end{array}$ & $\begin{array}{l}\text { Realizar Seminário com gestores das três } \\
\text { esferas e movimentos sociais }\end{array}$ \\
\hline \multirow{4}{*}{$\begin{array}{l}\text { Ausência ou } \\
\text { descontinuidade de } \\
\text { serviços de saúde na } \\
\text { região costeira } \\
\text { (Ausência de } \\
\text { infraestrutura básica } \\
\text { para os serviços de } \\
\text { saúde / ausência de } \\
\text { assistência com } \\
\text { relação à Saúde bucal } \\
\text { / desconhecimento } \\
\text { pelas autoridades } \\
\text { acerca da realidade } \\
\text { das comunidades) }\end{array}$} & $\begin{array}{l}\text { Realizar análise de situação da } \\
\text { organização de serviços de saúde } \\
\text { para estabelecer diálogo com } \\
\text { gestores locais }\end{array}$ & $\begin{array}{l}\text { Levantar dados do PSF; } \\
\text { Levantar mapas do Inea e PMP }\end{array}$ \\
\hline & $\begin{array}{l}\text { Realizar convite formal às } \\
\text { autoridades para visita às } \\
\text { comunidades }\end{array}$ & $\begin{array}{l}\text { Convidar para participar do Seminário e } \\
\text { Oficinas }\end{array}$ \\
\hline & $\begin{array}{l}\text { Fazer levantamento de informações } \\
\text { para subsidiar a implantação de } \\
\text { serviços }\end{array}$ & \\
\hline & Recorrer ao Ministério Público & \\
\hline $\begin{array}{l}\text { Redução da } \\
\text { incidência de } \\
\text { Agravos } \\
\text { (Leishmaniose } \\
\text { (informação / } \\
\text { assistência) / } \\
\text { aumento do número } \\
\text { de casos de câncer } \\
\text { (estômago) na região } \\
\text { costeira / Hanseniase }\end{array}$ & $\begin{array}{l}\text { Realizar análise situacional de saúde } \\
\text { das comunidades de Paraty } \\
\text { incluindo Angra e Ubatuba }\end{array}$ & \\
\hline \multirow{5}{*}{$\begin{array}{l}\text { Uso abusivo do } \\
\text { álcool e outras } \\
\text { drogas e promoção } \\
\text { da educação sexual }\end{array}$} & \multirow{5}{*}{$\begin{array}{l}\text { Promover ações de Educação em } \\
\text { Saúde }\end{array}$} & Buscar parceria com o CAPS; AA; Escolas \\
\hline & & $\begin{array}{l}\text { Envolver jovens, pais, tutores em atividades } \\
\text { educativas }\end{array}$ \\
\hline & & Promover e resgatar a cultural local \\
\hline & & $\begin{array}{l}\text { Fortalecer o turismo cultural, de base } \\
\text { comunitária }\end{array}$ \\
\hline & & $\begin{array}{l}\text { Estreitar a parceria com a Secretaria de } \\
\text { Turismo }\end{array}$ \\
\hline
\end{tabular}

parcerias em torno de uma rede cooperativa para a integração de agendas sociais e para fomentar projetos de promoção de territórios sustentáveis e saudáveis, por meio da troca de saberes e expe- riências sobre determinantes sociais da saúde, desenvolvimento sustentável e equidade em territórios vulneráveis, assim como da pactuação de estratégias. 
Quadro 2. Matriz de Análise de Projetos Sociais sob enfoque do Desenvolvimento Sustentável e da Promoção da Saúde

\begin{tabular}{|c|c|c|}
\hline Categorias & $\begin{array}{c}\text { Componentes do Projeto } \\
\text { Bocaina }\end{array}$ & Ideias-chave \\
\hline $\begin{array}{l}\text { Concepção } \\
\text { holística }\end{array}$ & $\begin{array}{l}\text { Objetivos: Geral e } \\
\text { Específicos, Antecedentes, } \\
\text { Metodologia, Estratégias para } \\
\text { promover a } \\
\text { intersetorialidade, Plano de } \\
\text { Ação }\end{array}$ & $\begin{array}{l}\text { 1. Desenvolvimento sustentável } \\
\text { 2. Promoção da Saúde } \\
\text { 3. Agenda Comunidades Saudáveis } \\
\text { 4. Agenda } 21 \text { local } \\
\text { 5. Promoção da qualidade de vida } \\
\text { 6. Construção de territórios saudáveis } \\
\text { 7. Políticas públicas saudáveis }\end{array}$ \\
\hline Intersetorialidade & $\begin{array}{l}\text { Objetivos: Geral e } \\
\text { Específicos, Antecedentes, } \\
\text { Metodologia, Estratégias para } \\
\text { promover a } \\
\text { intersetorialidade, Plano de } \\
\text { Ação }\end{array}$ & $\begin{array}{l}\text { 1. Plano de Ação das Comunidades Tradicionais e Áreas Protegidas } \\
\text { do Mosaico da Bocaina } \\
\text { 2. Câmara Temática de Populações Tradicionais do Conselho } \\
\text { Consultivo do Mosaico da Bocaina } \\
\text { 3. Estratégia de Saúde da Família } \\
\text { 4. Agenda } 21 \text { local } \\
\text { 5. Campanha Passaporte Verde } \\
\text { 6. Parcerias com as distintas esferas de governo } \\
\text { 7. Ministérios de Meio Ambiente e Turismo, Governo do Estado do } \\
\text { Rio de Janeiro, Prefeitura Municipal de Paraty }\end{array}$ \\
\hline Equidade & $\begin{array}{l}\text { Objetivos: Geral e Específicos } \\
\text {, População Participante, } \\
\text { Plano de Ação }\end{array}$ & $\begin{array}{l}\text { 1. Desenvolvimento equânime e sustentável } \\
\text { 2. Promoção da igualdade racial, política indigenista, } \\
\text { desenvolvimento agrário e direitos humanos } \\
\text { 3. Comunidades caiçaras, indígenas e quilombolas } \\
\text { 4. Inclusão social - acesso à terra, à saúde e à educação } \\
\text { 5. Identidade cultural preservada }\end{array}$ \\
\hline Participação & $\begin{array}{l}\text { Objetivos: Geral e } \\
\text { Específicos, Metodologia, } \\
\text { Estratégias para promover a } \\
\text { intersetorialidade, Plano de } \\
\text { Ação }\end{array}$ & $\begin{array}{l}\text { 1. Participação no SUS e nas políticas públicas } \\
\text { 2. Gestão participativa } \\
\text { 3. Controle social } \\
\text { 4. Envolver a comunidade no planejamento, gestão e avaliação da } \\
\text { implantação da Agenda Comunidades Saudáveis } \\
\text { 5. Identificar e divulgar oportunidades de qualificação da } \\
\text { participação social }\end{array}$ \\
\hline Empoderamento & $\begin{array}{l}\text { Objetivos: Geral e } \\
\text { Específicos, Metodologia, } \\
\text { Estratégias para promover a } \\
\text { intersetorialidade, Plano de } \\
\text { Ação }\end{array}$ & $\begin{array}{l}\text { 1. Ampliar a capacidade da população } \\
\text { 2. Desenvolver capacidades e habilidades } \\
\text { 3. Reforçar a capacidade sociocomunitária } \\
\text { 4. Envolver a comunidade no planejamento, gestão e avaliação da } \\
\text { implantação da Agenda Comunidades Saudáveis } \\
\text { 5. Ampliação do conhecimento da comunidade sobre as políticas } \\
\text { públicas locais }\end{array}$ \\
\hline Sustentabilidade & $\begin{array}{l}\text { Objetivos: Geral e } \\
\text { Específicos, Antecedentes, } \\
\text { Estratégias para promover a } \\
\text { intersetorialidade, Plano de } \\
\text { Ação }\end{array}$ & $\begin{array}{l}\text { 1. Integrar-se ao Plano de Ação do Encontro das Comunidades } \\
\text { Tradicionais e Áreas Protegidas do Mosaico da Bocaina } \\
\text { 2. Articular-se com a Câmara Temática de Populações Tradicionais } \\
\text { do Conselho Consultivo do Mosaico da Bocaina } \\
\text { 3. Integrar-se à Estratégia de Saúde da Família } \\
\text { 4. Integrar o Eixo Promoção da Qualidade de Vida ao Eixo } \\
\text { Promoção da Sustentabilidade Econômica Solidária } \\
\text { 5. Integrar-se à Agenda } 21 \text { local } \\
\text { 6. Integrar-se às ações da Campanha Passaporte Verde } \\
\text { 7. Turismo Sustentável } \\
\text { 8. Sustentabilidade ambiental } \\
\text { 9. Buscar parcerias com as distintas esferas de governo } \\
\text { 10. Buscar financiamento e apoio técnico }\end{array}$ \\
\hline
\end{tabular}


Gráfico 1. Percepção sobre o significado e Objetivos do Projeto

Objetivos do Projeto

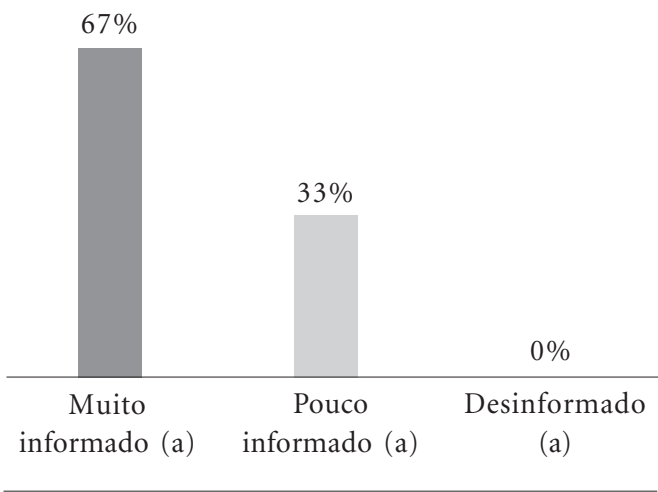

Gráfico 2. Grau de informação sobre

Desenvolvimento Sustentável

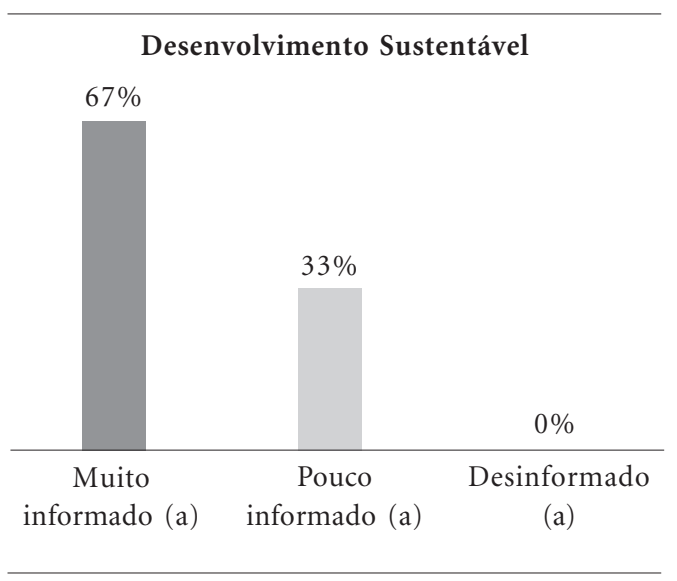

\section{Considerações Finais}

As respostas aos desafios colocados contemporaneamente pela convergência de Agendas de saúde, meio ambiente e desenvolvimento vêm sendo buscadas em diversas experiências que adotam abordagens capazes de promover a Justiça Socioambiental, a Equidade, a Autonomia e a Sustentabilidade a partir da Governança local.

As experiências de Cidades Saudáveis em curso na América Latina vêm crescendo na última década. Entretanto, poucas oferecem subsídios para análise e verificação do impacto das mudanças político-administrativas e culturais ou mesmo da capacidade dos cidadãos em se fortalecer e participar do processo de decisão em tor-
Gráfico 3. Grau de informação sobre Promoção da Saúde

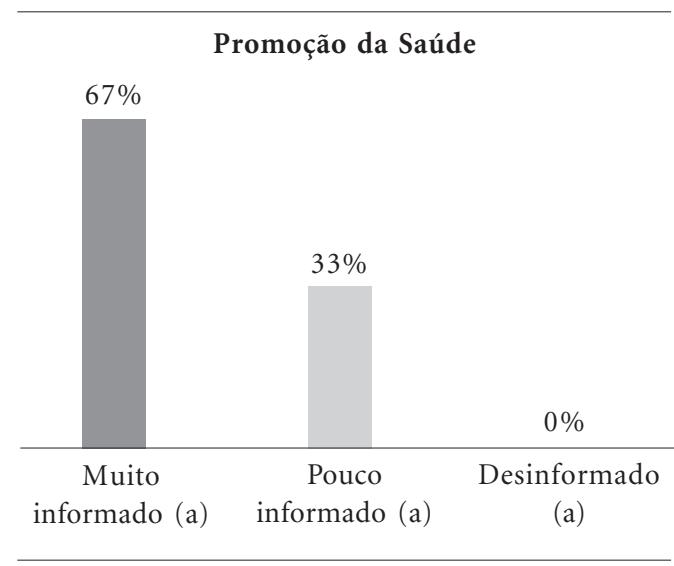

Gráfico 4. Grau de participação no Projeto

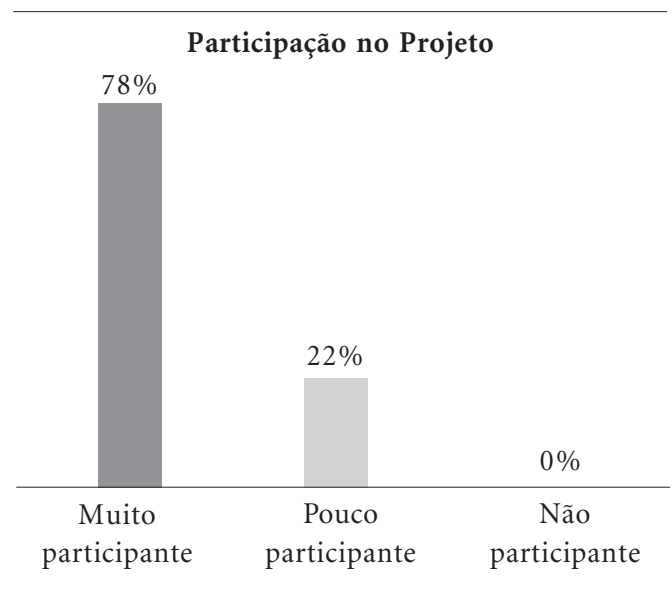

no dos assuntos referentes aos seus destinos e ao futuro da cidade ${ }^{26,41,42}$.

Para sua efetividade, estas abordagens precisam necessariamente: 1- promover intervenções concretas para a melhoria da qualidade de vida das comunidades; 2 - desenvolver capacidades e habilidades que ampliem a capacidade da população de participação no SUS e nas políticas públicas voltadas ao desenvolvimento equânime e sustentável do local; e 3- contribuir para reforçar a capacidade sociocomunitária na reivindicação, na gestão participativa e no controle social das políticas públicas voltadas para construção de territórios sustentáveis e saudáveis.

As abordagens ecossistêmica e comunicativa do planejamento estratégico-situacional, aplicadas 
a um território concreto, e aqui materializadas no Projeto Bocaina, permitiu a implantação da Agenda Comunidades Saudáveis e levou a indícios importantes de ampliação de autonomia e de avanços em direção à sustentabilidade e equidade.

A análise dos resultados e a avaliação da coerência e efetividade do projeto permitiram identificar, em sua implantação, alto grau de aderência aos pressupostos e categorias que constituem o marco teórico-prático adotado, assim como efetiva implantação da Agenda proposta, de forma participativa, o que resultou em maior empoderamento da população local e fortalecimento da intersetorialidade, bem como em um Plano de Ação consistente, com alcance de curto, médio e longo prazos.

\section{Colaboradores}

E Gallo e AFF Setti participaram igualmente de todas as etapas de elaboração do artigo.

\section{Agradecimentos}

Ao financiamento pelo edital de Cooperação Social para o Desenvolvimento Territorializado, da Coordenação de Cooperação Social da Presidência da Fiocruz. Aos pesquisadores Anna Cecília Cortines, Luiz Antonio Nolasco de Freitas e José Paulo Vicente da Silva.
A relevância do tema, as características das populações envolvidas e dos territórios, a articulação intergovernamental, a participação dos atores locais, a consistência do plano e o alcance dos resultados esperados deverão garantir a sustentabilidade política e técnica, assim como contribuir para a sustentabilidade organizacional do projeto na execução dos momentos subsequentes.

Pode-se concluir que estas abordagens e os momentos metodológicos apresentados têm potência para direcionar teórico-praticamente a implantação de agendas territorializadas, permitindo a pactuação de um Projeto emancipatório e ampliando a Capacidade de Governo local, em um processo que promova autonomia, equidade e sustentabilidade, contribuindo para o alcance da justiça socioambiental. 


\section{Referências}

1. Amim S. A economia política no século XX. In: Abramovay R; Arbix G, Zilbovicius M, organizadores. Razões e ficções do desenvolvimento. São Paulo: Editora Unesp, EDUSP; 2001. p. 179-195.

2. Merico LFK. Políticas Públicas para a sustentabilidade. In: Viana G, Silva M, Diniz N. O desafio da sustentabilidade: um debate socioambiental no Brasil. São Paulo: Editora Fundação Perseu Abramo; 2001. p. 251-262.

3. Robert KH. The natural step. A história de uma revolução silenciosa. São Paulo: Cultrix; 2002.

4. Minayo MCS. Enfoque ecossistêmico de saúde e qualidade de vida. In: Minayo MCS, Miranda AC, organizadores. Saúde e ambiente sustentável: estreitando nós. Rio de Janeiro: Editora Fiocruz; 2002.

5. Davenport L, Rao M. A história da proteção: paradoxos do passado e desafios do futuro. In: Terborgh J, Schaik C, organizadores. Curitiba: UFPR, Fundação O Boticário; 2002.

6. Bensusan N. Conservação da Biodiversidade em Áreas Protegidas. Rio de Janeiro: FGV; 2006.

7. Santos M. Por uma outra globalização: do pensamento único à consciência universal. 10a ed. Rio de Janeiro: Record; 2003.

8. Veiga JE. Desenvolvimento sustentável, o desafio do século XXI. 2a ed. Rio de Janeiro: Garamond; 2006.

9. Setti AFF, Gallo E. Desenvolvimento Sustentável e Promoção da Saúde: proposta de Matriz de Avaliação Qualitativa de Projetos Locais. In: Saúde em Debate, v. 33. Rio de Janeiro: CEBES, 2009.

10. CMMAD. Nuestro futuro común. Madri: Comisión Mundial del Medio Ambiente y del Desarrollo, Alianza Editorial; 1987.

11. Drexhage J, Murphy D. Sustainable Development: From Brundtland to Rio 2012. In: Background Paper prepared for consideration by the High Level Panel on Global Sustainability at its first meeting. New York: United Nations Headquarters; 2010.

12. Programa das Nações Unidas para o Desenvolvimento (PNUD). Agenda 21 brasileira: bases para discussão. Brasília: MMA, PNUD; 2000.

13. Setti AFF, Gallo E, Bógus CM. Avaliação Qualitativa de Projetos Locais sob o Olhar do Desenvolvimento Sustentável e da Promoção da Saúde: Estudo de Caso do Programa Bairro Ecológico, São Bernardo do Campo, SP, Brasil. In: Brasil VM, Gandara GS, organizadores. Cidades, Rios e Patrimônio Memórias e Identidades Beiradeiras. Goiânia, Editora da PUC; 2010. p. 189.

14. Franco Netto G. Meio ambiente, saúde e desenvolvimento sustentável. Cien Saude Colet 2009; 14(6): 1972-1982.

15. Programa das Nações Unidas para o Desenvolvimento (PNUD). Combater as alterações climáticas: solidariedade humana num mundo dividido. Relatório de Desenvolvimento Humano 2007/2008. [acessado em 2008 jun 01]. Disponível em: <http:// www.pnud.org.br/arquivos/rdh/rdh20072008/ hdr_20072008_pt_complete.pdf $>$.

16. United Nations (UN). United Nations Millennium Declaration. [acessado 2011 maio 14]. Disponível em: www.un.org/millenniumgoals/bkgd.shtml
17. Organização das Nações Unidas (ONU). Sustainable Development Summit Concludes in Johannesburg. Johannesburg: ONU; 2002.

18. World Health Organization (WHO). Carta de Ottawa. In: Ministério da Saúde, Fiocruz. Promoção da Saúde: Cartas de Ottawa, Adelaide, Sundsvall e Santa Fé de Bogotá. Brasília: Ministério da Saúde, IEC; 1996.

19. Gallo E, Costa JC, Castro JD, Studart V, Willecke S. Saúde, Desenvolvimento e Globalização. Saúde em Debate 2007; 29:315-326.

20. Feola G, Bazzani R, editores. Desafíos y estrategias para la implementación de un enfoque ecossistémico para la salud humana en los países em desarollo - reflexiones a propósito de las consultas regionales. Montevideo: CIID. [acessado 2011 mar 03]. Disponível em: http://www.idrc.ca/lacro/docs/conferencias/ecosalud. html,2002.

21. Organização Pan-Americana da Saúde (OPAS). Enfoques ecossistêmicos em saúde - perspectivas para sua adoção no Brasil e países da América Latina. Brasília: OPAS; 2009.

22. Brasil. Ministério da Saúde (MS). Secretaria de Vigilância em Saúde. Secretaria de Atenção à Saúde. Portaria n. 687, de 30 de março de 2006. Aprova a Política de Promoção da Saúde. 2a. ed. Brasília (DF): MS; 2007.

23. Comissão Nacional sobre Detereminantes Sociais da Saúde (CNDSS). As Causas Sociais das Iniquidades em Saúde no Brasil - Relatório Final, 2008. [acessado 2011 mar 03]. Disponível em: http:// www.cndss.fiocruz.br/pdf/home/relatorio.pdf

24. United Nations Conference on Trade and Development (UNCTAD). The Road to Rio+20 - For a development-led green economy. New York, Geneva: UNCTAD; 2011.

25. United Nations Envionment Panel (UNEP). Towards a Green Economy: Pathways to Sustainable Development and Poverty Eradication - A Synthesis for Policy Makers, 2011. [acessado 2011 fev 13]. Disponível em www.unep.org/greeneconomy.

26. Gallo E. Alienação, Inovação e Cotidiano Organizacional: Teses e Hipóteses. In: Mandarino ACS, Gomberg E, organizadores. Leituras de Novas Tecnologias e Saúde. Salvador: EDUFBA; 2009, p. 64-67.

27. Akerman M, Mendes R, Bógus CM, Westphal MF, Bichir A, Pedroso ML. Avaliação em promoção da saúde: foco no "município saudável". São Paulo: Rev Saude Publica 2002; 36(5):638-646.

28. Gallo E, Freitas LE, Reis R. Flexibilidade, Responsabilização e Autonomia: o caso da Diretoria de Investimentos e Projetos Estratégicos do Ministério da Saúde (DIPE - MS). Saúde em Debate 2006; 30:58-79.

29. Gallo E. Gestão Pública e Inovação. Tecnologias de Gestão e a Reinvenção do Cotidiano Organizacional [tese]. Rio de Janeiro: Escola Nacional de Saúde Pública da Fundação Oswaldo Cruz; 2009.

30. Possas CA. Social ecosystem health: confronting the complexity and emergence of infectious diseases. Cad Saude Publica 2001; 17(1):31-41.

31. Lebel J. Health - an ecosystem approach. Ottawa: International Development Research Centre; 2003. 
32. Waltner-Toews D. Ecosystem sustainability and health - a practical approach. Cambridge: Cambridge University Press; 2004.

33. Freitas CM. As Ciências Sociais e o Enfoque Ecossistêmico em Saúde. In: Minayo MCS, Coimbra Júnior CEA, organizadores. Criticas e Atuantes - Ciências Sociais e Humanas em Saúde na América Latina. Rio de Janeiro: Editora Fiocruz; 2005. p. 47-59.

34. Rede Brasileira de Justiça Ambiental (RBJA) [homepage na internet]. Rio de Janeiro: [acessado 2011 maio 14]. Disponível em: http://www.justicaambiental. org.br/_justicaambiental/pagina.php?id=229

35. Setti AFF. Análise de intervenção em área de mananciais no município de São Bernardo do Campo: o caso do Programa Bairro Ecológico [dissertação]. São Paulo (SP): Faculdade de Saúde Pública da Universidade de São Paulo; 2008.

36. Sachs I. Rumo à ecossocioeconomia. Teoria e prática do desenvolvimento. São Paulo: Cortez; 2007.

37. Gouveia N. Saúde e meio ambiente nas cidades: os desafios da saúde ambiental. Rev. Saúde e Sociedade 1999; 8(1):49-61.

38. Fórum de Comunidades Tradicionais do Sul Fluminense e Norte de São Paulo (FCTSFNSP). Relatório do I Encontro de Comunidades Tradicionais e Áreas Protegidas do Mosaico da Bocaina. Paraty: FCTSFNSP; 2006. mimeo.

39. Bodstein RCA. O debate sobre avaliação das práticas e estratégias em promoção da saúde. Boletim Técnico Senac: a R. Educ. Prof. Rio de Janeiro 2009; 35(2):6-15.

40. Sá RF, Moysés ST. O Processo avaliativo em promoção de saúde como estratégia de empoderamento e desenvolvimento de capacidades. Boletim Técnico Senac: a R. Educ. Prof. Rio de Janeiro 2009; 35(2): 28-35.

41. Organización Panamericana de la Salud (OPAS). Municipios y Comunidades Saludables. La evaluación participativa de los Municipios y Comunidades Saludabels: recursos prácticos para La acción. Lima: OPAS; 2005.

42. Fiocruz. Vice-Presidência de Ambiente, Atenção e Promoção da Saúde (VPAAPS). Política de Saúde e Ambiente da Fiocruz. Rio de Janeiro; 2010. [Apresentação de slides].

Artigo apresentado em 30/03/2012

Aprovado em 11/04/2012

Versão final apresentada em 04/05/2012 